\title{
Interacciones bióticas y simbióticas de nematodos
}

\author{
Biotic and symbiotic \\ interactions of nematodes
}

\author{
Alejandra Lara Coreño \\ alejandra29coreno@gmail.com \\ https://orcid.org/0000-0003-0837-8334
}

Universidad del Mar

Recibido: 3 de junio de 2021 Aceptado: 10 de agosto de 2021

Publicado: 5 de enero de 2022

\section{Resumen}

Las interacciones bióticas y simbióticas son las relaciones que se establecen entre individuos de diferentes especies, que pueden ser de corto o largo plazo. Estas pueden ser positivas o negativas. Se consideran positivas las interacciones relacionadas con el mutualismo (interacción simbiótica) y comensalismo (interacción biótica), mientras que se consideran negativas las interacciones parasitarias (interacción biótica). En este artículo se explicará cómo se llevan a cabo estos tres tipos de relaciones considerando como grupo principal a los nematodos. En el mutualismo veremos la interacción con bacterias, en comensalismo con invertebrados terrestres, y en parasitismo con el hombre y plantas. También se explicará las relaciones que pueden establecer con hongos.

Palabras clave: Relaciones interespecíficas, mutualismo, comensalismo, parasitismo.

Abstract
Biotic and symbiotic interactions are relationships
established between individuals of different species, which
can be short or long term. These relationships can be positive
or negative. Interactions related to mutualism (symbiotic)
and commensalism (biotic) are considered positive, while
parasitic interactions (biotic) are considered negative. This
article will explain these three types of relationships as they
relate to nematodes as the main group. Nematode interaction
with bacteria is an example of mutualism, with terrestrial
invertebrates commensalism, and interactions with humans
and plants are examples of parasitism. The relationships
nematodes can establish with fungi are also explained.
Keywords: Interspecific interactions,
commensalism, parasitism,

\section{Introducción}

Seguramente jamás te has preocupado por pedirle ayuda a tu gato para que juntos puedan alimentarse de un ratón. O mejor aún, jamás te has visualizado viviendo dentro del estómago de una vaca de la cual lógicamente te alimentarías día a día para poder sobrevivir. No es necesario, ya que somos individuos que podemos obtener alimento de manera individual, es decir, no necesitamos relacionarnos de manera cooperativa con otro individuo para poder obtener nuestro alimento. En la naturaleza no siempre es así, existen organismos que necesitan la ayuda de otros para poder alimentarse. De esta manera llegan a relacionarse (interacciones simbióticas) con otros seres vivos que pueden ser animales, hongos, plantas, bacterias o insectos, para poder sobrevivir. 
Aunque no lo creas, estos tipos de relaciones están en tu entorno, inclusive dentro de tu mismo cuerpo. Seguramente no te parecerá familiar el nombre de nematodos, pero es posible que sí conozcas a las lombrices intestinales; incluso es probable que hayas conocido a alguien que las ha padecido. Los nematodos son animales generalmente pequeños y de forma vermiforme. Pertenecen al filo Nematoda, el cual incluye una gran cantidad y diversidad de especies de gusanos cilíndricos. Algunos son de vida libre, varias especies se encuentran en aguas marinas. También hay representantes continentales y en suelo húmedo, así como un gran número de especies parásitas. Los nematodos son un modelo para explicar las interacciones bióticas (parasitismo, comensalismo) y simbióticas (mutualismo). En este texto se mencionan algunos ejemplos.

\section{Interacciones bióticas y simbióticas}

Las interacciones bióticas y simbióticas se caracterizan porque los organismos participantes viven en íntima asociación entre sí. Se establecen entre individuos de diferentes especies. Cuando ambos o únicamente uno es beneficiado y además no se causan daño se dice que son interacciones positivas; en cambio, cuando uno causa daño al otro se consideran negativas.

Las relaciones positivas pueden ser de dos tipos: 1) Mutualismo, en que ambos individuos se benefician. Un ejemplo es la relación entre las flores y las abejas. La abeja traslada polen de una flor a otra, fertilizándolas y, al mismo tiempo, la abeja se beneficia al alimentarse del néctar producido por la flor. 2) Comensalismo, un individuo se beneficia y el otro no es perjudicado; por ejemplo, algunos árboles proporcionan a los animales (monos, búhos, algunas aves e insectos) protección, así como un lugar para vivir y criar la descendencia. Para el árbol, en cambio, esta asociación es indiferente.

En el caso de las relaciones negativas puede tratarse del parasitismo, en el que un individuo se beneficia y el otro es perjudicado. Por ejemplo, los piojos y el zancudo que se alimentan de tu sangre son parásitos.

Una vez explicadas las características de las interacciones, señalaremos algunos ejemplos que los nematodos establecen en la naturaleza.

\section{Mutualismo de bacterias y nematodos}

Las relaciones mutualistas de los nematodos son muy interesantes. Por ejemplo, las bacterias (Xenorhabdus nematophila) y los nematodos (Steinernema carpocapsae) establecen una relación mutualista, la cual les permite matar insectos y utilizar los cadáveres como fuente de alimento. Hay que recalcar que este tipo de relación es obligada, pues ambos son totalmente dependientes el uno del otro, de manera que, si no existiese el nematodo, la bacteria no podría matar por sí sola a la víctima y esto lógicamente no le permitiría alimentarse, y si fuese que no existiese la bacteria sería la misma situación (Morran et al., 2016).

¿Cómo ocurre esto? El nematodo, en su ciclo de vida, presenta una etapa conocida como juvenil infecciosa. Durante esta etapa busca e ingresa en un insecto por medio de la boca, ano, orificios respiratorios (espiráculos), o por medio de las capas de la piel (cutícula). El nematodo viaja a través del líquido circulatorio (hemolinfa) del insecto y expulsa por la boca a la bacteria que se encuentra en el interior de su intestino, probablemente como respuesta de defensa por parte del sistema inmunitario del insecto al nematodo (Amador et al., 2015).

La bacteria comienza a multiplicarse en el líquido circulatorio y produce sustancias tóxicas (toxinas) que matan al insecto. Además, producen enzimas que degradan sus tejidos, antibióticos que preservan el cadáver del ataque de otros microorganismos y señales o nutrientes esenciales para el crecimiento, reproducción y desarrollo del nematodo dentro del cadáver del insecto (Murfin et al., 2012).

\section{Comensalismo de nematodos y milpiés}

Seguramente has visto alguna vez en tu vida los maravillosos milpiés (Clase Diplopoda= pies dobles), y si ya son animales increíbles por la cantidad de patas que presentan, imagínate que además de eso establecen una relación biótica con los nematodos. Un buen ejemplo de comensalismo es la supervivencia de los nematodos en el intestino de los milpiés.

¿Cómo ocurre esto? Los milpiés se alimentan de materia orgánica en descomposición (detritos). Algunas veces los nematodos depositan sus huevos en estos detritos y el milpiés se los come. Los huevos del nematodo se desarrollan en los intestinos de los milpiés. Al ser una relación de comensalismo, el nematodo no provoca ningún daño al milpiés, sino que obtiene beneficios al tener alimentos que ya han sido ingeridos y digeridos por este, sin provocarle ningún daño al milpiés (Phillips et al., 2019).

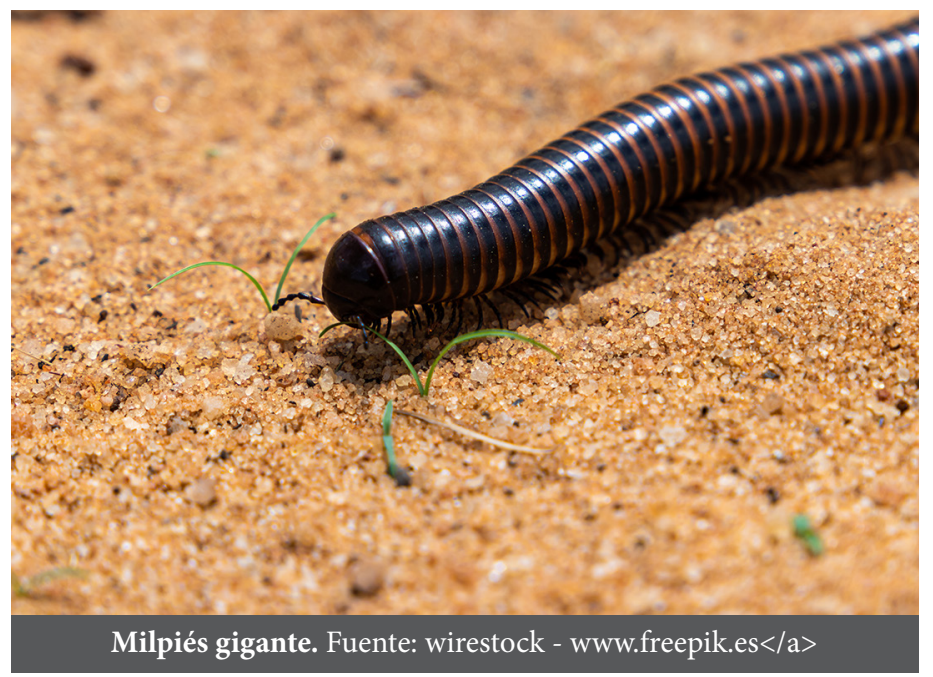




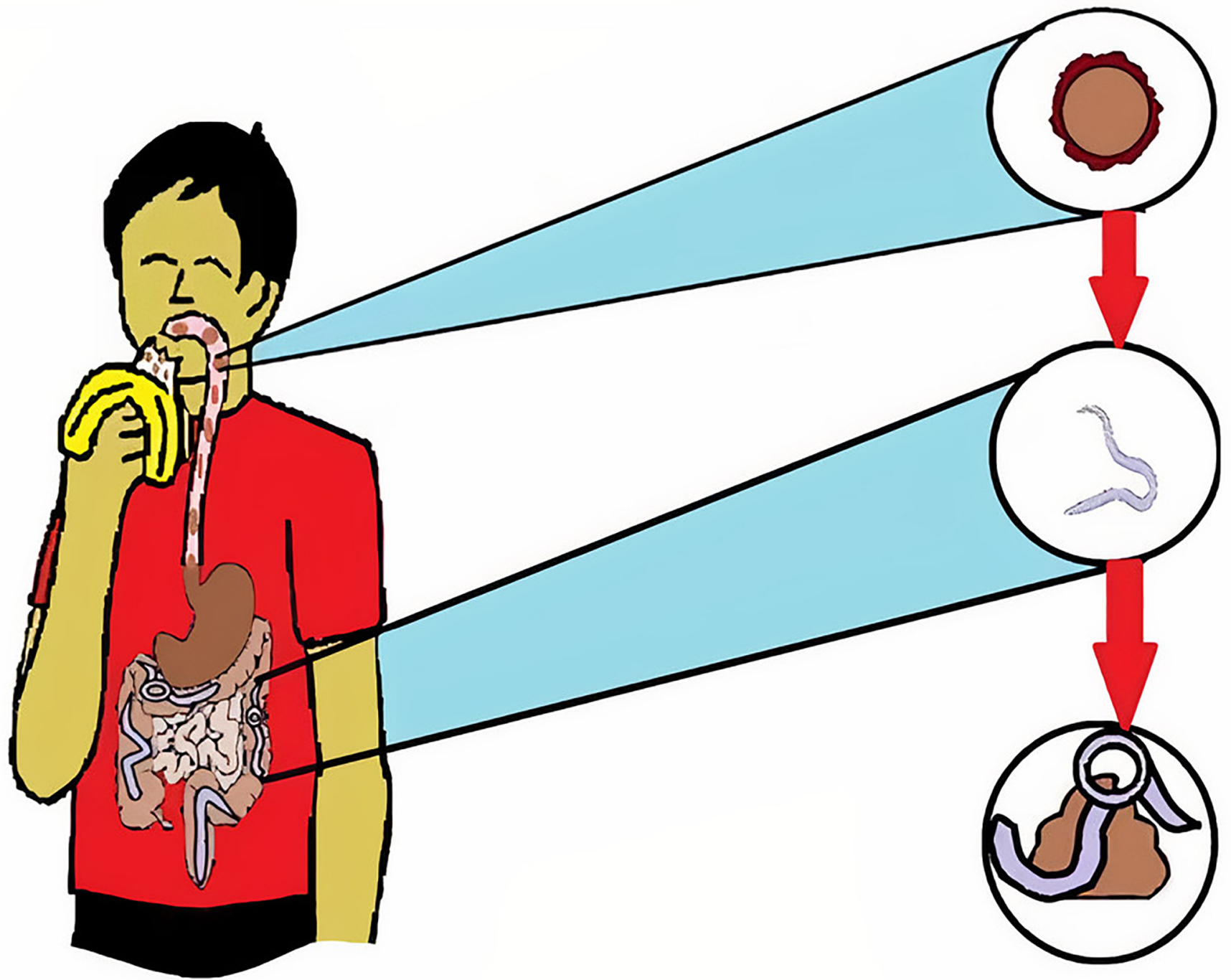

Parasitismo causado por ingesta de huevos de nematodos, estos recorren el intestino, se multiplican y se excretan por las heces. Autora: Alejandra Lara Coreño.

\section{Parasitismo}

Seguramente alguna vez tu mamá te ha dicho "eres un parásito: no haces nada, solo comes, pides dinero y duermes". Créeme que tu madre no está para nada equivocada. Pero es más interesante visualizar el parasitismo desde su perspectiva original, es decir, enfocado al mundo animal. Por ejemplo, los nematodos son amos y señores del parasitismo. La mayoría de ellos lo son, y solo una minoría no. Interesante, ¿no? Para comprender mejor cómo funciona esto, se mostrarán ejemplos de parasitismo en el ser humano y en plantas.

\section{Nematodos parásitos del hombre}

Los nematodos parásitos seguro te son familiares. Posiblemente los conozcas más como lombrices intestinales (Ascaris lumbricoides) y estos organismos parasitan con frecuencia al ser humano. El modo de contagio no se transmite de persona a persona, así que no te espantes. El contagio se da en realidad cuando ingerimos huevos de nematodos por medio de alimentos o agua contaminada, o bien si la persona se lleva las manos a la boca después de haber tocado alguna superficie contaminada (Dall'-Orso et al., 2014).

Una vez que nos hemos contagiado, los huevos viajan a nuestro intestino; ahí se convierten en larvas que migran por todo el cuerpo. Cuando llegan a la pared intestinal, pueden trasladarse a los pulmones, provocando síntomas respiratorios. De los pulmones pasan a los bronquios y suben a la garganta, en donde son deglutidos. Al regresar al intestino delgado, crecen, maduran y se reproducen. En pocas palabras, tú eres un hospedero muy atento que además los alimentas día a día. Las nematodos hembras de Ascaris lumbricoides ponen huevos (hasta 240 mil por día) que son arrojados en las heces. Todo el proceso puede durar de dos a tres meses.

Los síntomas de estar parasitado varían dependiendo de la gravedad de la infestación de huevecillos. Cuando es leve, podemos presentar síntomas como vómito o pérdida del apetito, flema con sangre, fiebre o dolor de estómago. Cuando es grave, se puede presentar dificultad para respirar, obstrucción intestinal y de las vías biliares. 


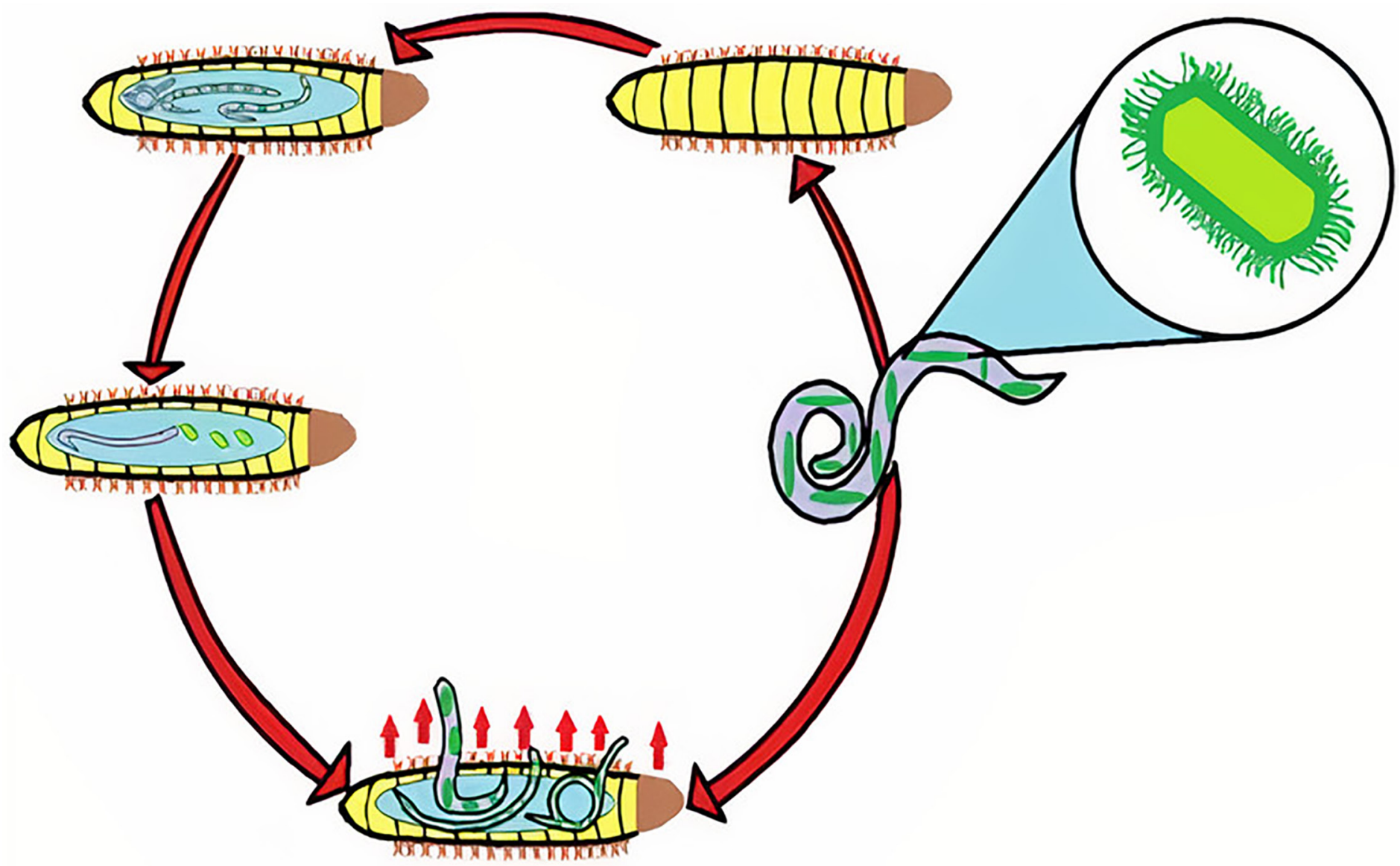

Mutualismo de nematodo (lila) y bacterias (verde) en el interior de un insecto (amarillo). Autora: Alejandra Lara Coreño.

\section{Parásitos nematodos de plantas}

Los nematodos también parasitan a las plantas. Viven en la película acuosa existente en el laberinto de microtúneles del suelo y dentro de los tejidos vegetales. Todos tienen una estructura protráctil hueca llamada estilete, la cual puede extenderse hacia afuera y permite al nematodo penetrar la raíz, así como perforar las células vegetales y extraer los nutrientes. Una vez que el estilete ha perforado la pared de la hoja de la planta, el nematodo inyecta enzimas que digieren parcialmente su contenido, antes de que él lo succione hacia su sistema digestivo. Este proceso de alimentación puede realizarse desde fuera de la planta (ectoparásitos) o desde

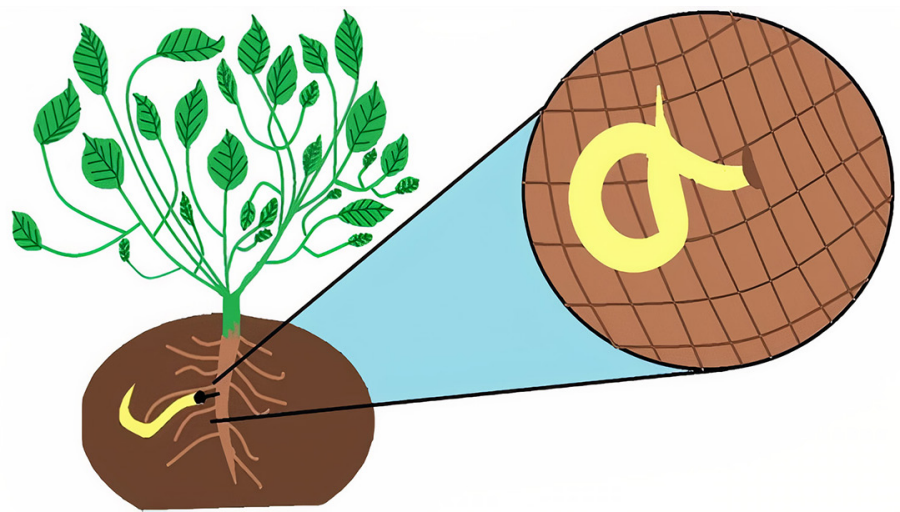

Nematodo (amarillo) parasitando la raíz de una planta por medio del estilete (negro). Autora: Alejandra Lara Coreño. dentro (endoparásitos). Un ejemplo de endoparasitismo es el que realiza la especie de nematodo Ditylenchus dipsaci, el cual infecta principalmente a la planta de ajo (Allium sativum) y de cebolla (Allium cepa). En el caso del ectoparasitismo, un ejemplo es el que realiza el nematodo de la especie Pratylenchus penetrans, el cual infecta a la planta de papa (Solanum tuberosum). Los daños que provocan los nematodos a las plantas están relacionados con el proceso de la alimentación, pues disminuye la capacidad de las raíces para captar y transportar nutrientes al resto del vegetal, lo que provoca un debilitamiento general y pérdidas de producción (Talavera-Rubia, 2003).

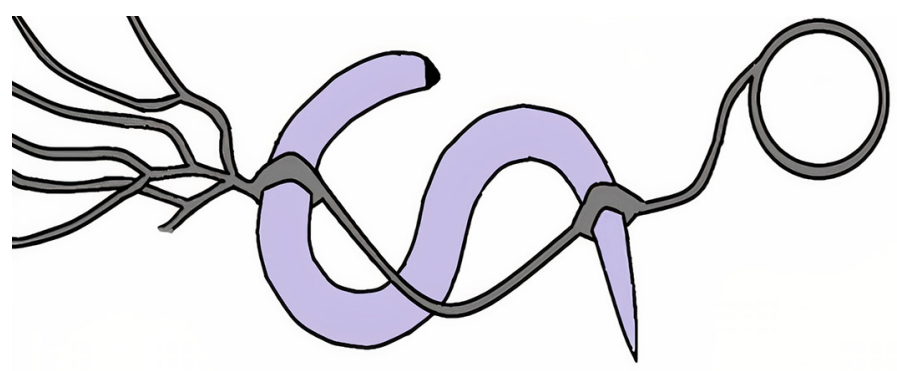

Hongo parasitando a nematodo (lila) a través del micelio (gris). Autora: Alejandra Lara Coreño. 


\section{Hongos atrapadores de nematodos}

Pero no todo lo que brilla en este mundo es oro. Si bien ya hemos dicho que la mayoría de los nematodos son parásitos, no siempre es así. En algunas ocasiones, llegan a ser víctimas de otros parásitos como los hongos. ¿Cómo ocurre esto? Los hongos pertenecientes al grupo Deuteromycetes desarrollan mecanismos de captura especializados (micelios), los cuales se forman a partir de unas estructuras filamentosas que a simple vista parecen algodón. En el hongo surgen unas estructuras derivadas del micelio en formas de anillos. Estas permanecen abiertas hasta que el nematodo entra en ellos. Una vez que el hongo recibe la señal de que el nematodo ha caído en su trampa, el hongo cierra los anillos y lo aprieta. Pero eso no es todo, el hongo penetra la piel (cutícula del nematodo) y comienza a expandir su micelio por todo el cuerpo del animal, de manera que lo coloniza y se nutre de él. Cuando muere, el hongo tendrá que buscar una nueva víctima (Jiang et al., 2017).

\section{Conclusiones}

Las interacciones bióticas y simbióticas son de vital importancia para todos los seres vivos que habitan el planeta Tierra, principalmente porque han sido una pieza clave para su supervivencia. Si no existiesen, seguramente muchas especies estarían extintas, por lo tanto, no pueden ni deben subestimarse. Su función principal en la naturaleza es proporcionar alimentos, además de mantener el equilibrio. Las relaciones bióticas y simbióticas pueden ayudar a las especies a evolucionar, a cambiar e incluso a prosperar. Sin estas interacciones no habría arrecifes de coral, es posible que los árboles no proliferaran tanto como lo hacen, ayudados por las aves y los insectos que transportan semillas lejos, e incluso los seres humanos podrían no haber sobrevivido lo suficiente para evolucionar hasta llegar a ser la especie que ahora somos.

\section{Referencias}

Amador, M., Molina, D., Guillen, C., Parajeles, E., Jiménez, K. y Uribe, L. 2015. Utilización del nematodo entomopatógeno Heterorhabditis atacamensis CIA-NE07 en el control del picudo del banano Cosmopolites sordidus en condiciones in vitro. Agronomía Costarricense, 39 (3): 47-60.

Dall'-Orso, P., Cantou, V., Rosano, K., De los Santos, K., Fernández, N., Berazategui, R. y Giachetto, G. 2014. Ascaris lumbricoides. Complicaciones graves en niños hospitalizados en el Centro Hospitalario Pereira Rossell. Archivos de Pediatría del Uruguay, 85 (3): 149-154.

Jiang, X., Xiang, M. y Liu, X. 2017. Nematode-Trapping Fungi. En: Xiang, M, Jiang, X. y Liu, X. (eds.). The Fungal Kingdom. John Wiley \& Sons, Hoboken, Nueva Jersey, pp. 963-974.

Morran, L. T., Penley, M., Byrd, V. S., Meyer, A. J., O’ Sullivan, T. S., Bashey, F., Goodrich-Blair, H. y Lively, C. M. 2016. NematodeBacteria Mutualism: Selection Within the Mutualism Supersedes Selection Outside of the Mutualism. Evolution, 70 (3): 687-695.

Murfin, K. E., Dillman, A. R., Foster, J. M., Bulgheresi, S., Slatko, B. E., W. Sternberg, P. W. y Goodrich-Blair, H. 2012. Nematode-Bacterium Symbioses - Cooperation and Conflict Revealed in the "Omics" Age. The Biological Bulletin, 223 (1): 85-102.

Phillips, G., Yates, D. I., Shelley, R. M., Ortstadt, P. R. y Bernard, E. C. 2019. Investigating Commensal Relationships of Nematodes in Millipedes: Life in Unexpected Places. The American Biology Teacher, 81 (4): 278-283.

Talavera-Rubia, M. F. 2003. Manual de Nematologia AgrícolaIntroducción al Análisis y al Control Nematológico para Agricultores y Técnicas de Agrupaciones de Defensa Vegetal. Institut de Recerca i Formació Agrária i Pesquera de les Illes Balears pp. 28.

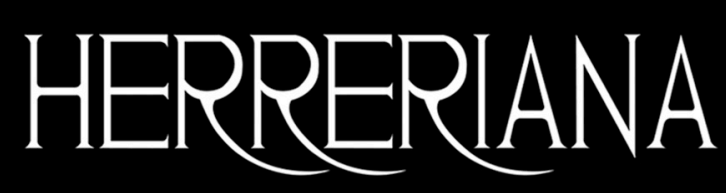

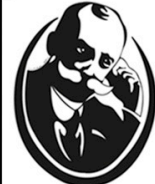

